\title{
Relationship between LRRK2 R1628P polymorphism and Parkinson's disease in Asian populations
}

\author{
Hui Zhao ${ }^{1}$ and Zhijun Kong ${ }^{2}$ \\ ${ }^{1}$ Department of General Surgery, Third Affiliated Hospital of Nantong University, Wuxi, China \\ 2 Department of General Surgery, Affiliated Hospital of Nanjing Medical University, Changzhou Second People's Hospital, \\ Changzhou, China \\ Correspondence to: Zhijun Kong, email: kongzhijun623@sina.com \\ Keywords: LRRK2; polymorphism; Parkinson's disease; meta-analysis; R1628P; Gerotarget \\ Received: April 10, $2016 \quad$ Accepted: June 07, $2016 \quad$ Published: July 01, 2016
}

\section{ABSTRACT}

Although the leucine-rich repeat kinase 2 (LRRK2) R1628P polymorphism has been associated with the risk of Parkinson's disease (PD) in Taiwan, China, and Singapore, there are conflicting findings regarding this relationship. Thus, the aim of the present meta-analysis was to evaluate the associations between the LRRK2 R1628P polymorphism (rs33949390) and PD in Asian populations. A search for eligible studies was performed in PubMed, Embase, SinoMed, and the China Knowledge Resource Integrated Database, and pooled odds ratios and $95 \%$ confidence intervals were used to evaluate the strength of the association between the R1628P polymorphism and PD. This meta-analysis assessed 19 studies from 14 papers that involved a total of 9,927 PD patients and 8,602 controls and found that the R1628P polymorphism was significantly associated with the risk of PD in Asian populations. Moreover, stratification analyses indicated that the R1628P polymorphism was significantly associated with an increased risk of PD among Chinese as well as non-Chinese Asian populations and an increased risk of PD in Chinese patients from China, Taiwan, and Singapore. In a stratified analysis conducted according to age, significant associations were found for both late-onset PD and early-onset PD. The present data indicate that the R1628P polymorphism of the LRRK2 gene contributes to PD susceptibility in Asian, especially Chinese, populations.

\section{INTRODUCTION}

Parkinson's disease (PD), which is one of the most common neurodegenerative disorders, is characterized by tremors, rigidity, bradykinesia, and postural instability [1]. It has been estimated that approximately 9.3 million individuals older than 50 years of age around the world will suffer from PD by 2030 [2]. Although the etiology of PD remains poorly understood, genetic variations likely play important roles in its development [3]. For example, mutations in the leucine-rich repeat kinase 2 (LRRK2) gene lead to autosomal dominant PD [4, 5]. Studies have demonstrated that polymorphisms of the LRRK2 gene are related to an increased presence of PD compared with control groups [6].
Recently, a study from three independent centers in Taiwan and Singapore demonstrated that LRRK2 R1628P (rs33949390) polymorphism was a genetic risk factor for PD [7]. Subsequent studies have further investigated the association between the $\mathrm{R} 1628 \mathrm{P}$ polymorphism and the risk of PD but produced conflicting results [8-20]. However, these discrepancies may be due inadequate statistical power, different ethnic populations, and small sample sizes. To overcome these limitations and to resolve the inconsistencies among previous studies, we conducted this meta-analysis to investigate whether the LRRK2 $\mathrm{R} 1628 \mathrm{P}$ polymorphism is associated with susceptibility to PD. 


\section{RESULTS}

\section{Characteristics of the published studies}

A total of 368 papers were yielded after our initial search. After removing duplicates and screening the titles and abstracts, 345 papers were removed. Therefore, 23 papers were selected for further full text review. Four papers were not case-control studies [21-24]; one was a review [25]; four did not provide detailed genotype data [26-29]. Finally, we identified fourteen eligible papers [7-20] including nineteen studies in this meta-analysis. Selection for eligible papers included in this meta-analysis was presented in Figure 1. The characteristics of these included papers are summarized in Table 1. These papers were published from 2008 to 2014. All included studies conformed to HWE. The NOS scores of all included studies ranged from 5 to 7 stars, indicating that they were studies of high methodological quality. Seven studies were carried out in China [8, 9, 14, 17-20], three in Singapore $[7,19]$, and six in Taiwan [7, 11-13, 19]; the remaining three studies were carried out in Malaysia [15], Thailand [10] and South Korea [16].
Meta-analysis: LRRK2 R1628P polymorphism (rs33949390)

A fixed effects model was conducted for allele model (C vs. G), dominant model (CC + CG vs. GG) and heterozygous model (CG vs. GG) without significant heterogeneity. Due to the deficiency of CC genotypes in included studies, we could not calculate the data of recessive model and homozygous model. As shown in Table 2, R1628P polymorphism was significantly associated with PD risk (C vs. G: OR, 1.97; 95\% CI, 1.702.28, $P<0.00001$, Figure 2; $\mathrm{CC}+\mathrm{GC}$ vs. GG: OR, 1.97; 95\% CI, 1.70-2.28, $P<0.00001$; GC vs. GG: OR, 1.93; $95 \% \mathrm{CI}, 1.67-2.24, P<0.00001)$. Stratification analyses were conducted according to ethnicity, age and country (Table 2). The results indicated that R1628P polymorphism was significantly associated with the increased risk of PD among Chinese as well as non-Chinese $(\mathrm{C} v s$. G, Figure 3). Furthermore, we found that R1628P polymorphism might increase the risk of PD patients from China, Taiwan, and Singapore. In the stratified analysis by age, we also found that R1628P polymorphism was associated with PD risk. We assessed sensitivity by omitting each study once at a time in every genetic model. The pooled ORs

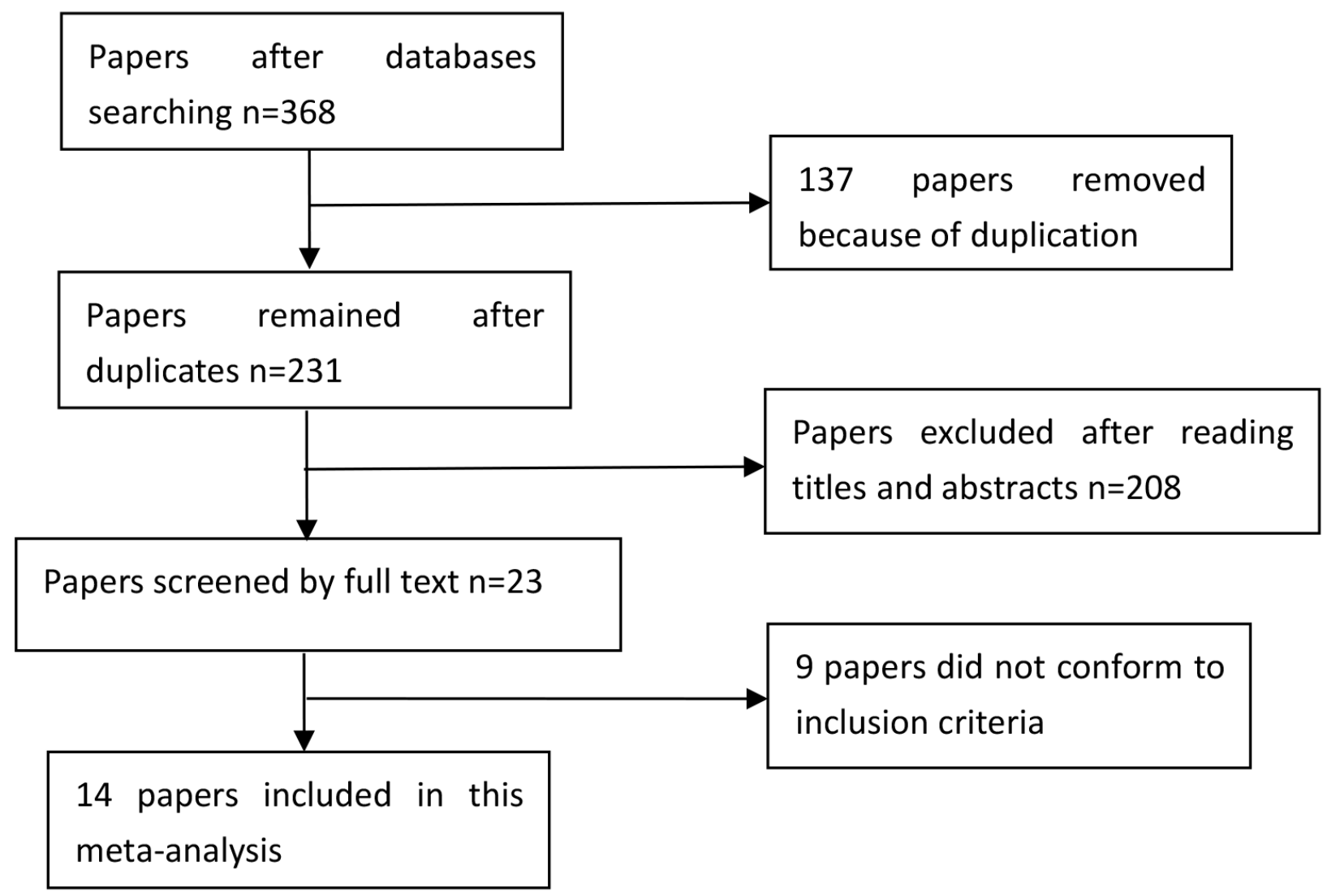

Figure 1: Selection for eligible papers included in this meta-analysis. 
Table 1: Characteristics of included studies.

\begin{tabular}{|l|l|l|l|l|l|l|l|l|l|l|}
\hline Author and year & Country & Case & & & Control & & & HWE & Genotypes Methods & NOS \\
\hline & & GG & GC & CC & GG & GC & CC & & & \\
\hline Gopalai2014 & Malaysia & 659 & 35 & 1 & 489 & 18 & 0 & 0.684 & PCR & 6 \\
\hline Wu2013 & Taiwan & 539 & 34 & 0 & 481 & 22 & 0 & 0.616 & PCR & 6 \\
\hline Cai2013 & China & 482 & 28 & 0 & 532 & 18 & 0 & 0.696 & PCR-RFLP & 6 \\
\hline Wu-Chou2013 & Taiwan & 689 & 56 & 2 & 443 & 18 & 0 & 0.669 & TaqMan & 6 \\
\hline Fu2013 & China & 399 & 47 & 0 & 382 & 21 & 0 & 0.591 & PCR & 5 \\
\hline Wang2012 & China & 1949 & 63 & 1 & 1940 & 31 & 0 & 0.725 & PCR & 7 \\
\hline Zhou2012 & China & 200 & 2 & 0 & 207 & 5 & 0 & 0.862 & PCR & 6 \\
\hline Pulkes2011 & Thailand & 139 & 14 & 1 & 151 & 5 & 0 & 0.834 & Na & 6 \\
\hline Tan2010 & Singapore & 226 & 24 & 0 & 235 & 15 & 0 & 0.625 & MALDI-TOF & 6 \\
\hline Tan2010 & Singapore & 163 & 28 & 1 & 173 & 18 & 1 & 0.484 & MALDI-TOF & 6 \\
\hline Tan2010 & Taiwan & 270 & 23 & 0 & 281 & 18 & 0 & 0.592 & MALDI-TOF & 6 \\
\hline Tan2010 & China & 579 & 48 & 1 & 500 & 10 & 0 & 0.823 & MALDI-TOF & 5 \\
\hline Kim2010 & South Korea & 380 & 3 & 0 & 378 & 1 & 0 & 0.980 & PCR & 7 \\
\hline Yu2009 & China & 311 & 17 & 0 & 294 & 6 & 0 & 0.861 & PCR-RFLP & 5 \\
\hline Zhang2009 & China & 557 & 40 & 3 & 448 & 11 & 0 & 0.795 & PCR & 6 \\
\hline Ross2008 & Taiwan & 452 & 31 & 1 & 330 & 11 & 0 & 0.762 & RFLP & 6 \\
\hline Ross2008 & Taiwan & 324 & 21 & 0 & 302 & 14 & 0 & 0.687 & RFLP & 6 \\
\hline Ross2008 & Singapore & 237 & 13 & 0 & 244 & 6 & 0 & 0.848 & RFLP & 6 \\
\hline Lu2008 & Taiwan & 772 & 60 & 2 & 523 & 20 & 0 & 0.662 & PCR & 6 \\
\hline
\end{tabular}

HWE, Hardy-Weinberg equilibrium; NOS, Newcastle-Ottawa Scale; Na, not available

Table 2: Meta-analysis of associations between the R1628P polymorphism and PD risk.

\begin{tabular}{|l|l|l|l|l|l|l|}
\hline Comparison & $\begin{array}{l}\text { Overall and Stratification } \\
\text { analyses }\end{array}$ & Studies & OR $(\mathbf{9 5 \%}$ CI) & P-value & $\begin{array}{l}\mathbf{P} \\
\text { heterogeneity }\end{array}$ & I2 (\%) \\
\hline C vs. G & Overall & 19 & $1.97(1.70,2.28)$ & $<0.00001$ & 0.41 & 4.0 \\
\hline & Chinese & 16 & $1.97(1.69,2.30)$ & $<0.00001$ & 0.34 & 10.0 \\
\cline { 2 - 7 } & Non-Chinese & 3 & $1.91(1.18,3.08)$ & 0.009 & 0.37 & 0.0 \\
\hline & Chinese in China & 7 & $2.33(1.84,2.94)$ & $<0.00001$ & 0.14 & 38.0 \\
\hline & Chinese in Taiwan & 6 & $1.75(1.38,2.22)$ & $<0.00001$ & 0.64 & 0.0 \\
\hline & Chinese in Singapore & 3 & $1.67(1.12,2.49)$ & 0.01 & 0.83 & 0.0 \\
\hline & EOPD & 3 & $2.00(1.05,3.83)$ & 0.04 & 0.68 & 0.0 \\
\hline & LOPD & 3 & $2.48(1.24,4.95)$ & 0.01 & 0.09 & 59.0 \\
\hline & Overall & 19 & $1.97(1.70,2.28)$ & $<0.00001$ & 0.49 & 0.0 \\
\hline & Chinese & 16 & $1.98(1.69,2.31)$ & $<0.00001$ & 0.41 & 4.0 \\
\cline { 2 - 7 } & Non-Chinese & 3 & $1.86(1.14,3.03)$ & 0.01 & 0.39 & 0.0 \\
\hline & Chinese in China & 7 & $2.33(1.84,2.94)$ & $<0.00001$ & 0.16 & 36.0 \\
\hline & Chinese in Taiwan & 6 & $1.74(1.37,2.21)$ & $<0.00001$ & 0.70 & 0.0 \\
\hline & Chinese in Singapore & 3 & $1.73(1.15,2.62)$ & 0.009 & 0.86 & 0.0 \\
\hline & EOPD & 3 & $2.03(1.05,3.90)$ & 0.03 & 0.67 & 0.0 \\
\hline & LOPD & 3 & $2.45(1.26,4.74)$ & 0.008 & 0.12 & 54.0 \\
\hline & Overall & 19 & $1.93(1.67,2.24)$ & $<0.00001$ & 0.57 & 0.0 \\
\hline & Chinese & 16 & $1.99(1.68,2.36)$ & $<0.00001$ & 0.62 & 0.0 \\
\hline & Non-Chinese & 3 & $1.79(1.09,2.93)$ & 0.02 & 0.43 & 0.0 \\
\hline & Chinese in China & 7 & $2.28(1.80,2.89)$ & $<0.00001$ & 0.19 & 32.0 \\
\hline & Chinese in Taiwan & 6 & $1.71(1.34,2.17)$ & $<0.0001$ & 0.77 & 0.0 \\
\hline & Chinese in Singapore & 3 & $1.75(1.16,2.65)$ & 0.008 & 0.87 & 0.0 \\
\hline & EOPD & 3 & $2.06(1.09,3.92)$ & 0.03 & 0.67 & 0.0 \\
\hline & LOPD & 3 & $2.37(1.54,3.66)$ & $<0.0001$ & 0.16 & 46.0 \\
\hline
\end{tabular}

EOPD, early-onset Parkinson's disease; LOPD, late-onset Parkinson's disease; OR, odds ratio; 95\% CI, 95\% confidence interval. 
for the effect of R1628P polymorphism on the risk for PD indicated that our data were stable and trustworthy (Figure 4). Both Egger's and Begg's tests were used to evaluate the publication bias of this meta-analysis. The results revealed that there was no obvious publication bias in overall analysis for R1628P polymorphism (C vs. G, $P_{\text {begg }}=0.753$ and $P_{\text {egger }}=0.964$, Figure 5; CC + CG vs. GG, $P_{\text {begg }}^{\text {begg }}=0.649$ and $P_{\text {egger }}^{\text {egger }}=0.987 ;$ CG vs. GG, $P_{\text {begg }}=0.552$ and $\left.P_{\text {egger }}=0.984\right)$.

\section{DISCUSSION}

$\mathrm{PD}$ is a progressive neurodegenerative disease, which is caused primarily by the loss of dopaminergic neurons in the substantia nigra compacta and the presence of intracellular inclusions known as Lewy bodies. Although the potential etiology of PD remains poorly understood, PD is thought to be caused by both genetic and environmental factors. To date, several candidate genes including $L R R K 2$ have been reported to be associated with the risk of PD [30].Many studies have demonstrated that genetic risk factors play a crucial role in the susceptibility to PD, and recently, the role of $L R R K 2$ gene variants in the development of PD have sparked a great deal of interest [31]. The LRRK2 gene encodes a large multidomain protein that includes an ankyrin repeat (ANK), a leucine-rich repeat (LRR), Ras of complex proteins (ROC; GTPase), C-terminal of ROC (COR), mitogen-activated kinase kinase kinase (MAPKKK), and WD40 domains [32, 33]. The R1628P polymorphism is located in the COR region. Some studies shown that the R1628P may affect the interaction between the different functional domains of LRRK2 or its interaction with other proteins, which in turn, may result in altered LRRK2 protein function [29].

Many studies investigated the relationship between the LRRK2 R1628P polymorphism and the risk of PD in Asian individuals [7-20], but produced contradictory results. Therefore, it was necessary to conduct a metaanalysis to determine whether this polymorphism is associated with PD susceptibility in Asian populations. The findings of the present meta-analysis suggested that LRRK2 R1628P polymorphism was associated with an increased risk of PD among Asian populations. Previous meta-analyses [26, 34] investigating the R1628P polymorphism in terms of PD susceptibility produced conflicting findings. Ross et al. [26] analyzed 1,376 PD cases and 962 controls and found that R1628P is not associated with a risk of $\mathrm{PD}$ in Asian populations, while Wu et al. [34] determined that this polymorphism actually increases the risk of PD in Asians, which is consistent with the present findings. The findings of the present metaanalysis and $\mathrm{Wu}$ et al. are likely more robust than those of Ross et al. due to the use of larger sample sizes.

The stratification analyses in this meta-analysis also indicated that the R1628P polymorphism is significantly

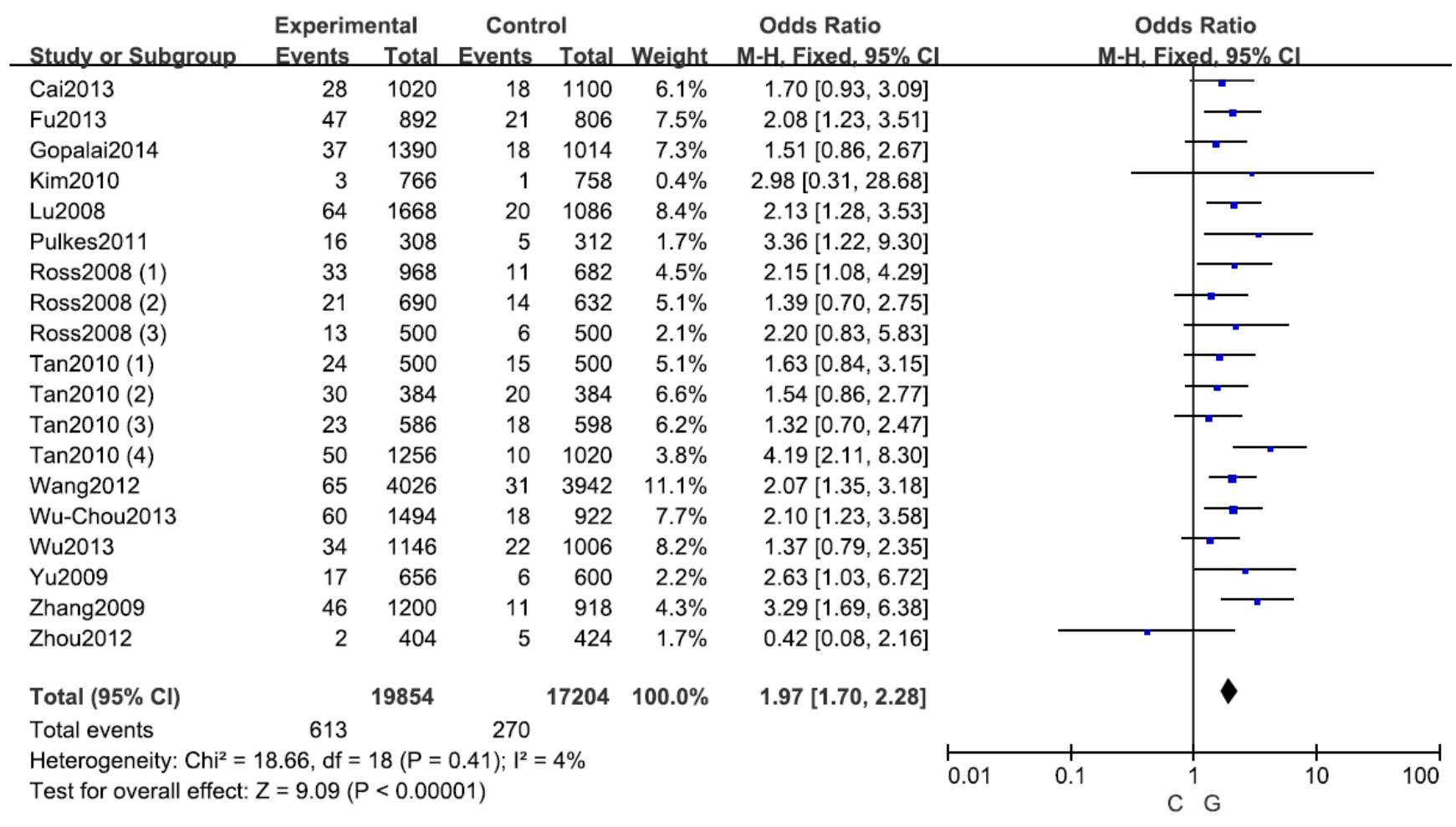

Figure 2: Forest plot shows odds ratio for the associations between $L R R K 2$ R1628P polymorphism and PD risk (C vs. G) 
associated with increased risks of PD among Chinese and non-Chinese individuals, which was not found by $\mathrm{Wu}$ et al. [34]. However, the associations among the SNPs in genes associated with disorders were greatly affected by the number of subjects in the study. The results of this meta-analysis of non-Chinese individuals should be interpreted with caution because only three of the analyzed studies included non-Chinese subjects (1,232 PD cases and 1,402 controls). Furthermore, two studies investigating Japanese subjects suggested that the R1628P variant is not associated with susceptibility to PD [7, 27]. Tan et al. also demonstrated that R1628P was not a genetic risk factor for Malaysian and Indian populations [28]. However, these three studies did not provide detailed genotype data, and thus, it is not advisable to exclude the possibility that the $\mathrm{R} 1628 \mathrm{P}$ polymorphism is not related to the risk of $\mathrm{PD}$ in non-Chinese ethnicities if the present meta-analysis had included these data $[7,27,28]$. Therefore, it is reasonable to assume that the $L R R K 2 \mathrm{R} 1628 \mathrm{P}$ polymorphism may be a specific risk factor of PD among Chinese individuals, which suggests the need for future larger-scale studies to validate this assumption. The stratified analysis in the present meta-analysis also indicated that the R1628P polymorphism increases the risk of PD in Chinese patients from China, Taiwan, and Singapore. In the stratified analysis that was conducted according to age, significant associations were found in both late-onset and early-onset PD cases, but this finding should be interpreted with caution due to limited sample sizes. A sensitivity analysis indicated that the present data were stable and trustworthy.

The present meta-analysis has several limitations that should be should be taken into consideration. First, this study did not investigate the association between the LRRK2 R1628P polymorphism and PD in Caucasian populations. Second, unpublished trials may have been excluded unintentionally and could have resulted in a

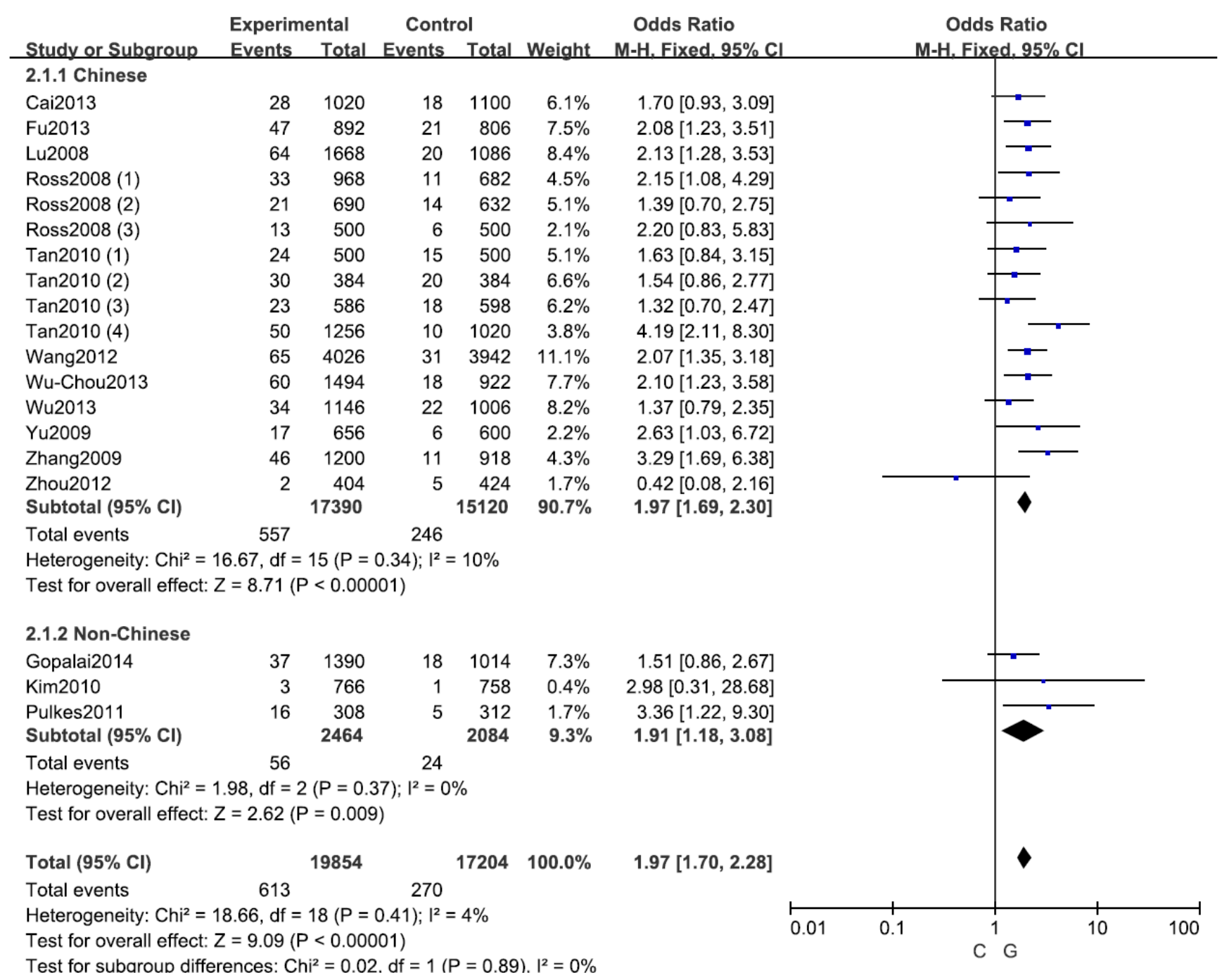

Figure 3: Stratification analyses of ethnicity between $L R R K 2$ R1628P polymorphism and PD risk (C vs. G) 

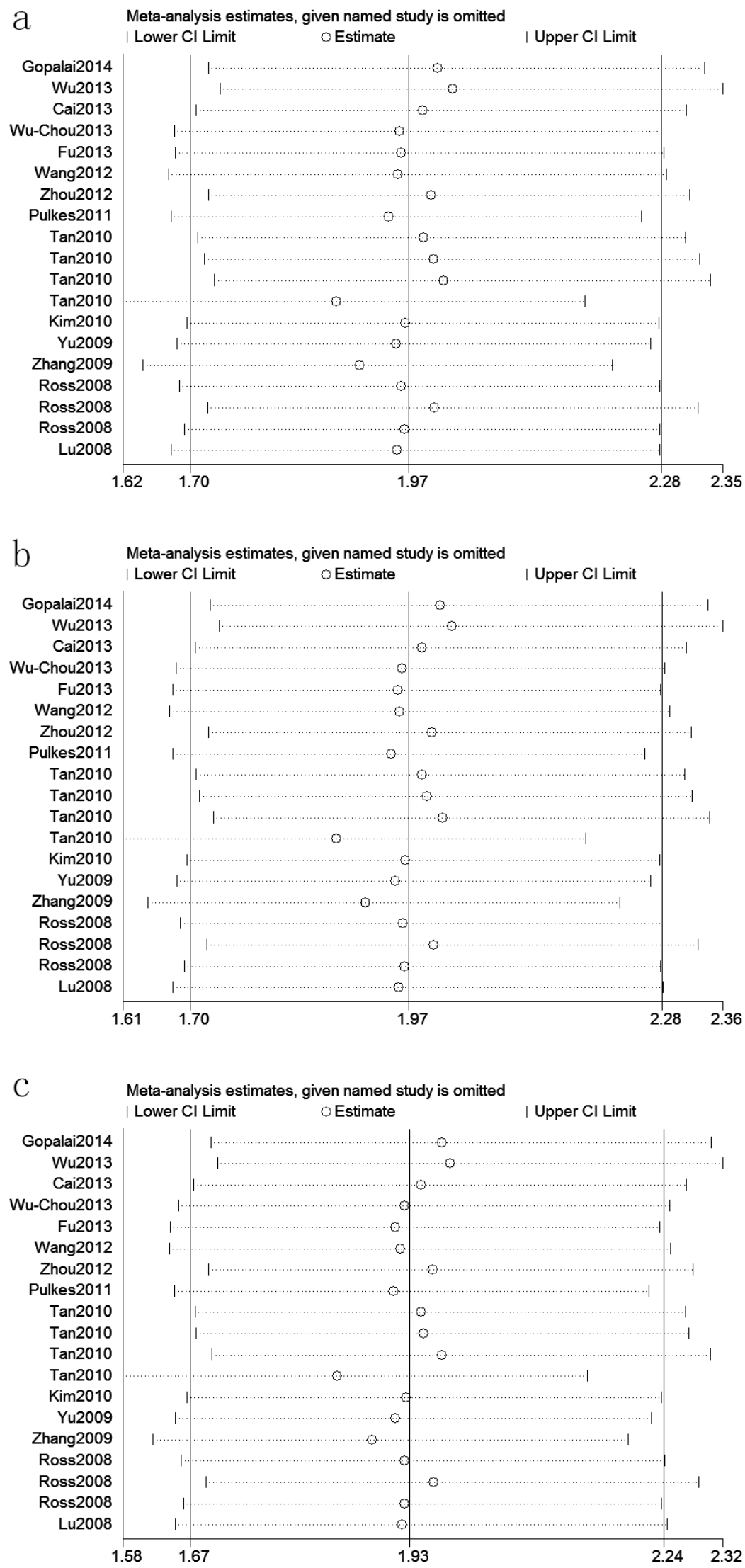

Figure 4: Sensitivity analyses between $L R R K 2$ R1628P polymorphism and PD risk (C vs. G; b: CC+GC vs. GG; c: GC vs. GG) 
publication bias; however, there was no evidence of this. Third, the present findings were based on unadjusted estimates that did not consider confounding factors such as age, sex, or environmental factors, and thus, the analysis could have been more precise if individual data were available. Fourth, the results of the stratified analyses should be interpreted with caution due to limited sample sizes. Future larger-scale studies are urgently needed to confirm these results. Fifth, it is impossible to include all the languages when we performed the literature search.

In conclusion, this meta-analysis indicates that LRRK2 R1628P polymorphism is significantly associated with an increased risk of PD in Asians, especially among Chinese subjects. Future large-scale studies are necessary to characterize the association between the LRRK2 R1628P polymorphism and PD.

\section{MATERIALS AND METHODS}

\section{Literature search}

We performed a comprehensive search in PubMed, Embase, SinoMed, and the China Knowledge Resource Integrated Database to identify studies through March 1, 2016 that were related with the LRRK2 gene polymorphism and PD. The following search terms were used:
"Leucine-rich repeat kinase 2," "LRRK2," "PARK8," "Parkinson's disease," "Parkinson disease," "PD,"“SNP," and "polymorphism". Two independent investigators conducted the search. No language or other restrictions were placed on the search. We also performed a manual search of references cited in published papers to identify other initially omitted studies. Any disagreements were resolved by consensus. Criteria for the inclusion in this analysis were: (1) studies that evaluated the association between LRRK2 R1628P polymorphism (rs33949390) and PD in Asian populations, (2) studied on human beings, (3) study provided sufficient data to calculate the Odds ratios (ORs) and 95\% confidence intervals (CIs), and $P$ value, and (4) case-control study. Exclusion criteria were: (1) duplication of previous publications; (2) review, editorial, or other non-original studies; (3) studies without detailed genotype data; (4) studies without controls.

\section{Data extraction and quality assessment}

For all eligible studies, the extracted information including: name of first author, publication year, country of origin, and $L R R K 2$ R1628P genotype frequency in cases and controls. Extraction of the data was independently performed by two authors according to the inclusion criteria. All included studies were evaluated using the

Newcastle-Ottawa Scale (NOS) [35]. They

Begg's funnel plot with pseudo $95 \%$ confidence limits

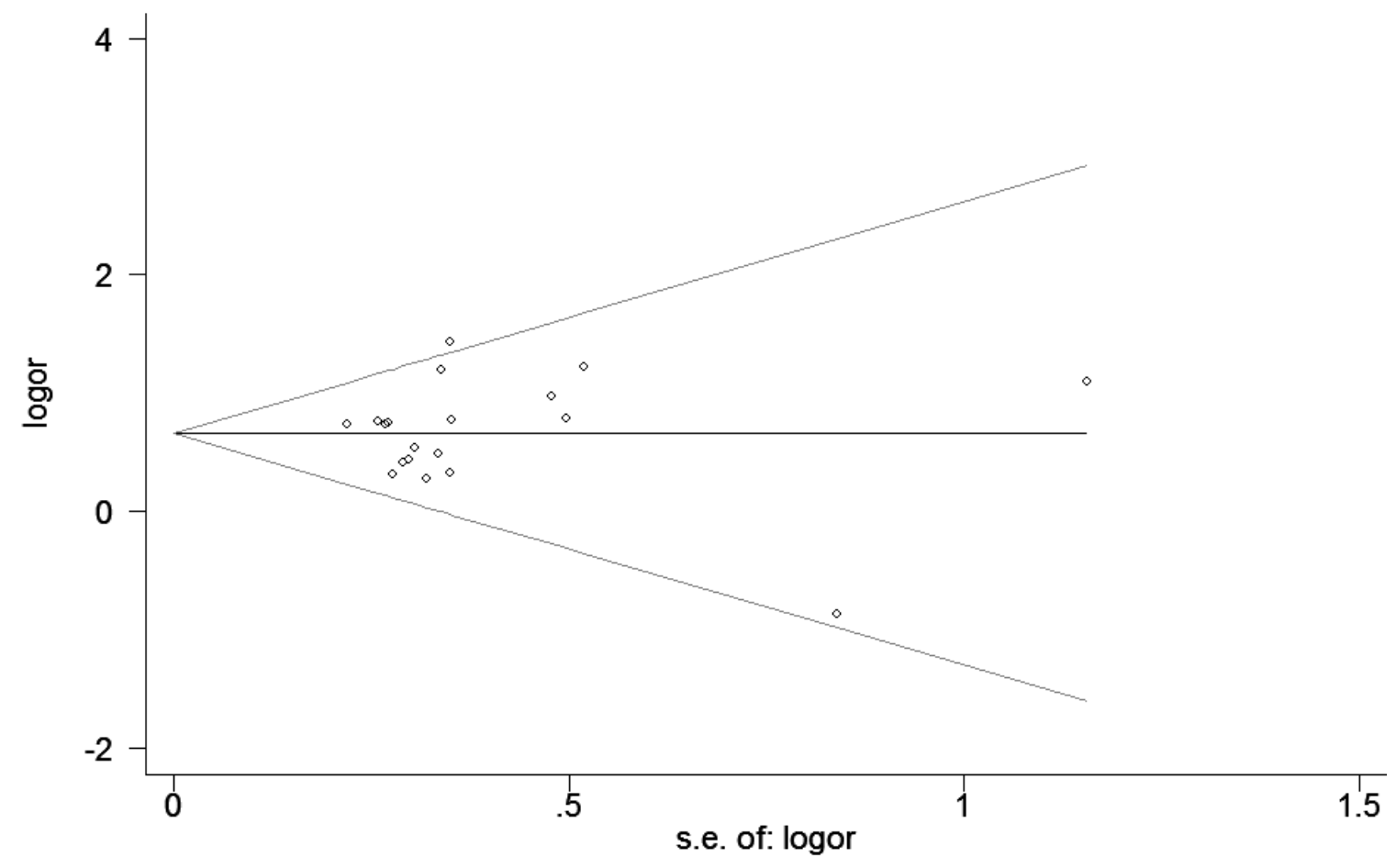

Figure 5: Begg's tests for publication bias between LRRK2 R1628P polymorphism and PD risk (C vs. G) 
compared results and agreed on a consensus; disagreements were resolved by discussion.

\section{Statistical analysis}

All statistical analyses were performed using the Stata 11.0 software (StataCorp, College Station, TX, USA) and RevMan 5.3 (The Nordic Cochrane Centre, Copenhagen, Denmark). Pooled ORs and 95\% CIs were calculated to evaluate the strength of the association between LRRK2 R1628P polymorphism (rs33949390) and PD. Heterogeneity was evaluated by the Q statistic (significant at $P<0.1$ ) and $\mathrm{I}^{2}$ statistic (where $>50 \%$ indicates significant heterogeneity) [36]. A fixed-effect model was used for comparing the trials without showing heterogeneity, whereas a random effect model was selected for comparing trials showing heterogeneity. Pooled ORs were calculated for allele model, dominant model, recessive model, homozygous model, and heterozygous model. We performed sensitivity analyses by omitting each study in turn to determine the effect on the test of heterogeneity and evaluated the stability of the overall results. Hardy-Weinberg equilibrium (HWE) was assessed in the controls using Pearson's $\chi^{2}$ test. Potential publication bias was investigated with the use of Begger's and Egger's linear regression test [37]. A $P$ value $<0.05$ was considered to indicate statistically significant.

\section{Abbreviations}

CI, confidence interval; OR, odds ratio; PD, Parkinson's disease; LRRK2, Leucine-rich repeat kinase 2; NOS, Newcastle-Ottawa Scale; HWE, Hardy-Weinberg equilibrium

\section{CONFLICTS OF INTEREST}

The authors declare no conflict of interest.

\section{REFERENCES}

1. Luk KC, Kehm V, Carroll J, Zhang B, O'Brien P, Trojanowski JQ and Lee VM. Pathological alpha-synuclein transmission initiates Parkinson-like neurodegeneration in nontransgenic mice. Science. 2012; 338:949-953.

2. Dorsey ER, Constantinescu R, Thompson JP, Biglan KM, Holloway RG, Kieburtz K, Marshall FJ, Ravina BM, Schifitto G, Siderowf A and Tanner CM. Projected number of people with Parkinson disease in the most populous nations, 2005 through 2030. Neurology. 2007; 68:384-386.

3. Bekris LM, Mata IF and Zabetian CP. The genetics of Parkinson disease. Journal of geriatric psychiatry and neurology. 2010; 23:228-242.

4. Paisan-Ruiz C, Jain S, Evans EW, Gilks WP, Simon J, van der Brug M, Lopez de Munain A, Aparicio S, Gil AM, Khan N, Johnson J, Martinez JR, Nicholl D, Carrera IM, Pena AS, de Silva R, et al. Cloning of the gene containing mutations that cause PARK8-linked Parkinson's disease. Neuron. 2004; 44:595-600.

5. Zimprich A, Biskup S, Leitner P, Lichtner P, Farrer M, Lincoln S, Kachergus J, Hulihan M, Uitti RJ, Calne DB, Stoessl AJ, Pfeiffer RF, Patenge N, Carbajal IC, Vieregge $\mathrm{P}$, Asmus F, et al. Mutations in LRRK2 cause autosomaldominant parkinsonism with pleomorphic pathology. Neuron. 2004; 44:601-607.

6. Gilks WP, Abou-Sleiman PM, Gandhi S, Jain S, Singleton A, Lees AJ, Shaw K, Bhatia KP, Bonifati V, Quinn NP, Lynch J, Healy DG, Holton JL, Revesz T and Wood NW. A common LRRK2 mutation in idiopathic Parkinson's disease. Lancet. 2005; 365:415-416.

7. Ross OA, Wu YR, Lee MC, Funayama M, Chen ML, Soto AI, Mata IF, Lee-Chen GJ, Chen CM, Tang M, Zhao Y, Hattori N, Farrer MJ, Tan EK and Wu RM. Analysis of Lrrk2 R1628P as a risk factor for Parkinson's disease. Annals of neurology. 2008; 64:88-92.

8. Cai J, Lin Y, Chen W, Lin Q, Cai B, Wang N and Zheng W. Association between G2385R and R1628P polymorphism of LRRK2 gene and sporadic Parkinson's disease in a HanChinese population in south-eastern China. Neurological sciences. 2013; 34:2001-2006.

9. Zhou Y, Luo X, Li F, Tian X, Zhu L, Yang Y, Ren Y and Pang H. Association of Parkinson's disease with six single nucleotide polymorphisms located in four PARK genes in the northern Han Chinese population. Journal of clinical neuroscience. 2012; 19:1011-1015.

10. Pulkes T, Papsing C, Mahasirimongkol S, Busabaratana M, Kulkantrakorn $\mathrm{K}$ and Tiamkao S. Frequencies of LRRK2 variants in Thai patients with Parkinson's disease: evidence for an R1628P founder. Journal of neurology, neurosurgery, and psychiatry. 2011; 82:1179-1180.

11. Wu-Chou YH, Chen YT, Yeh TH, Chang HC, Weng YH, Lai SC, Huang CL, Chen RS, Huang YZ, Chen CC, Hung J, Chuang WL, Lin WY, Chen $\mathrm{CH}$ and Lu CS. Genetic variants of SNCA and LRRK2 genes are associated with sporadic PD susceptibility: a replication study in a Taiwanese cohort. Parkinsonism \& related disorders. 2013; 19:251-255.

12. Wu YR, Chang KH, Chang WT, Hsiao YC, Hsu HC, Jiang $\mathrm{PR}$, Chen YC, Chao CY, Chang YC, Lee BH, Hu FJ, Chen WL, Lee-Chen GJ and Chen CM. Genetic variants ofLRRK2 in Taiwanese Parkinson's disease. PloS one. 2013; 8:e82001.

13. Lu CS, Wu-Chou YH, van Doeselaar M, Simons EJ, Chang HC, Breedveld GJ, Di Fonzo A, Chen RS, Weng YH, Lai SC, Oostra BA and Bonifati V. The LRRK2 Arg1628Pro variant is a risk factor for Parkinson's disease in the Chinese population. Neurogenetics. 2008; 9:271-276.

14. Fu X, Zheng Y, Hong H, He Y, Zhou S, Guo C, Liu Y, Xian W, Zeng J, Li J, Liu Z, Chen L and Pei Z. LRRK2 G2385R 
and LRRK2 R1628P increase risk of Parkinson's disease in a Han Chinese population from Southern Mainland China. Parkinsonism \& related disorders. 2013; 19:397-398.

15. Gopalai AA, Lim SY, Chua JY, Tey S, Lim TT, Mohamed Ibrahim N, Tan AH, Eow GB, Abdul Aziz Z, Puvanarajah SD, Viswanathan S, Looi I, Lim SK, Tan LP, Chong YB, Tan CT, et al. LRRK2 G2385R and R1628P mutations are associated with an increased risk of Parkinson's disease in the Malaysian population. BioMed research international. 2014; 2014:867321.

16. Kim JM, Lee JY, Kim HJ, Kim JS, Shin ES, Cho JH, Park SS and Jeon BS. The LRRK2 G2385R variant is a risk factor for sporadic Parkinson's disease in the Korean population. Parkinsonism \& related disorders. 2010; 16:8588.

17. Yu L, Hu F, Zou X, Jiang Y, Liu Y, He X, Xi J, Liu L, Liu Z, He L and Xu Y. LRRK2 R1628P contributes to Parkinson's disease susceptibility in Chinese Han populations from mainland China. Brain research. 2009; 1296:113-116.

18. Zhang Z, Burgunder JM, An X, Wu Y, Chen W, Zhang J, Wang Y, Xu Y, Gou Y, Yuan G, Mao X and Peng R. LRRK2 R1628P variant is a risk factor of Parkinson's disease among Han-Chinese from mainland China. Movement disorders. 2009; 24:1902-1905.

19. Tan EK, Peng R, Teo YY, Tan LC, Angeles D, Ho P, Chen ML, Lin CH, Mao XY, Chang XL, Prakash KM, Liu JJ, $\mathrm{Au}$ WL, Le WD, Jankovic J, Burgunder JM, et al. Multiple LRRK2 variants modulate risk of Parkinson disease: a Chinese multicenter study. Human mutation. 2010; 31:561568.

20. Wang C, Cai Y, Zheng Z, Tang BS, Xu Y, Wang T, Ma J, Chen SD, Langston JW, Tanner CM, Chan P and Chinese Parkinson Study G. Penetrance of LRRK2 G2385R and $\mathrm{R} 1628 \mathrm{P}$ is modified by common PD-associated genetic variants. Parkinsonism \& related disorders. 2012; 18:958963.

21. Choi JM, Woo MS, Ma HI, Kang SY, Sung YH, Yong SW, Chung SJ, Kim JS, Shin HW, Lyoo CH, Lee PH, Baik JS, Kim SJ, Park MY, Sohn YH, Kim JH, et al. Analysis of PARK genes in a Korean cohort of early-onset Parkinson disease. Neurogenetics. 2008; 9:263-269.

22. Zheng Y, Pei Z, Liu Y, Zhou H, Xian W, Fang Y, Chen $\mathrm{L}$ and $\mathrm{Wu} \mathrm{Q}$. Cognitive Impairments in LRRK2-Related Parkinson's Disease: A Study in Chinese Individuals. Behavioural neurology. 2015; 2015:621873.

23. Ma LY, Chan P, Gu ZQ, Li FF and Feng T. Heterogeneity among patients with Parkinson's disease: cluster analysis and genetic association. Journal of the neurological sciences. 2015; 351:41-45.

24. Gao C, Pang H, Luo XG, Ren Y, Shang H and He ZY. LRRK2 G2385R variant carriers of female Parkinson's disease are more susceptible to motor fluctuation. Journal of neurology. 2013; 260:2884-2889.
25. Peeraully $\mathrm{T}$ and Tan EK. Genetic variants in sporadic Parkinson's disease: East vs West. Parkinsonism \& related disorders. 2012; 18 Suppl 1:S63-65.

26. Ross OA, Soto-Ortolaza AI, Heckman MG, Aasly JO, Abahuni N, Annesi G, Bacon JA, Bardien S, Bozi M, Brice A, Brighina L, Van Broeckhoven C, Carr J, ChartierHarlin MC, Dardiotis E, Dickson DW, et al. Association of LRRK2 exonic variants with susceptibility to Parkinson's disease: a case-control study. The Lancet Neurology. 2011; 10:898-908

27. Zabetian CP, Yamamoto M, Lopez AN, Ujike H, Mata IF, Izumi Y, Kaji R, Maruyama H, Morino H, Oda M, Hutter CM, Edwards KL, Schellenberg GD, Tsuang DW, Yearout D, Larson EB, et al. LRRK2 mutations and risk variants in Japanese patients with Parkinson's disease. Movement disorders. 2009; 24:1034-1041.

28. Tan EK, Tang M, Tan LC, Wu YR, Wu RM, Ross OA and Zhao Y. Lrrk2 R1628P in non-Chinese Asian races. Annals of neurology. 2008; 64:472-473.

29. Tan EK, Tan LC, Lim HQ, Li R, Tang M, Yih Y, Pavanni R, Prakash KM, Fook-Chong $\mathrm{S}$ and Zhao Y. LRRK2 R1628P increases risk of Parkinson's disease: replication evidence. Human genetics. 2008; 124:287-288.

30. Gao J, Nalls MA, Shi M, Joubert BR, Hernandez DG, Huang X, Hollenbeck A, Singleton AB and Chen H. An exploratory analysis on gene-environment interactions for Parkinson disease. Neurobiology of aging. 2012; 33:2528 e2521-2526.

31. Dachsel JC and Farrer MJ. LRRK2 and Parkinson disease. Archives of neurology. 2010; 67:542-547.

32. Guo L, Wang W and Chen SG. Leucine-rich repeat kinase 2: relevance to Parkinson's disease. The international journal of biochemistry \& cell biology. 2006; 38:14691475.

33. Mata IF, Wedemeyer WJ, Farrer MJ, Taylor JP and Gallo KA. LRRK2 in Parkinson's disease: protein domains and functional insights. Trends in neurosciences. 2006; 29:286293.

34. Wu X, Tang KF, Li Y, Xiong YY, Shen L, Wei ZY, Zhou KJ, Niu JM, Han X, Yang L, Feng GY, He L and Qin SY. Quantitative assessment of the effect of LRRK2 exonic variants on the risk of Parkinson's disease: a meta-analysis. Parkinsonism \& related disorders. 2012; 18:722-730.

35. Stang A. Critical evaluation of the Newcastle-Ottawa scale for the assessment of the quality of nonrandomized studies in meta-analyses. European journal of epidemiology. 2010; 25:603-605.

36. Higgins JP and Thompson SG. Quantifying heterogeneity in a meta-analysis. Statistics in medicine. 2002; 21:1539-1558.

37. Peters JL, Sutton AJ, Jones DR, Abrams KR and Rushton L. Comparison of two methods to detect publication bias in meta-analysis. Jama. 2006; 295:676-680. 